\title{
ESTUDIO EN BLANCO Y NEGRO: TEATRO DE VIRGILIO PIÑERA
}

\author{
POR \\ RAQUEL CARRIO MENDIA \\ Instituto Superior de Artes, La Habana
}

\begin{abstract}
Para los poetas y dramaturgos, en vez de homenajes yo organizaría ataques y desafios en los cuales se nos dijera gallardamente y con verdadera saña: ¿AA que no tienes el valor de hacer esto?" "¿A que no eres capaz de expresar la angustia del mar en un personaje?»...
\end{abstract}

Federico García LoRCA ${ }^{1}$

Si hay una figura polémica en el contexto de la literatura y el teatro contemporáneo en Cuba lo es Virgilio Piñera (1912-1979). Discutidor, provocador él mismo, polemista en el arduo sentido del término, su obra - poética, dramática, narrativa - reproduce la angustia y la intensidad de un hombre inserto en su contexto, su cultura, su espacio y tiempo históricos; las interrogantes y respuestas que más de cuarenta años después de la escritura de La isla en peso y Electra Garrigó continúan inquietando, movilizando al lector, creándole una zona para el diálogo y la reflexión.

En cierto sentido, Piñera tuvo suerte. No le faltaron ataques y desafíos, pero tampoco el valor y la osadía de enfrentarlos. Apologistas y detractores pueden rendirse a la. evidencia: ni obra fácil, que admita la aceptación condescendiente, acrítica, ni mucho menos un autor sobre el que pueda tenderse el discreto velo de una figura «de época». Resistentes, sus piezas siguen siendo lo que fueron siempre: enigmas para el espectador, juego

1 Federico García Lorca, «Charla sobre teatro», en Obras completas (Madrid: Aguilar, 1962), p. 33. 
de espejos en el que se encuentran apresadas algunas de las constantes significaciones más complejas de nuestra historia.

Cuando en 1941 Piñera escribe Electra Garrigó nace el teatro moderno en Cuba. Hasta entonces, una larga tradición sostiene la polaridad entre una línea «culta», apegada a las formas de modelos clásicos, románticos y realistas, y una expresión vernácula, popular, cuyas primeras manifestaciones se remontan a las representaciones bufas del siglo anterior. Entre uno y otro camino, búsquedas y tentativas de integración; esfuerzos nobles por crear una verdadera dramática nacional que ejemplifica la obra de José Antonio Ramos, representante de una primera generación republicana. Tembladera (1917) y La recurva (1939) tipifican la actitud, el gesto airado de una intelectualidad que se resiste al dominio imperialista, la deformación de la estructura socioeconómica del país y la crisis de valores de una conciencia nacional. El tema de la tierra y el ámbito familiar ocupan el centro de atención. La familia - célula social- refracta y sintetiza conflictos y contradicciones de un orden mayor. A más de un sentido de abierta denuncia social, la dramaturgia de Ramos establece un área de confrontaciones. La indagación sobre la «cubanidad», los problemas que afectan la plena integración de una cultura nacional, constituyen el legado más fértil de su producción.

Aparentemente, nada tendrían que ver las robustas piezas de Ramos con los inicios de un autor que se propone «divertir» al espectador con la parodia jubilosa de un clásico griego: coro que se transforma en una espléndida guantanamera, columnas que soportan una antigua casa colonial, y la extrañeza del traje típico, la fruta del país, la palangana que sustituye el casco del Atrida. ¿Qué explica el cambio de tono grave, de severo censor de las costumbres que encontramos en Ramos, en este otro en que asistimos al reverso, es decir, la «sistemática ruptura» de lo trágico por lo cómico, la «reducción al absurdo», el juego teatral, recursos que distinguen la dramaturgia de Piñera? ${ }^{2}$

El propio autor, en el prólogo a su Teatro completo (1960), ofrece señales de interés. No se trata de un alejamiento, un abandono de preocupaciones medulares, sino de un replanteo de la problemática (social, familiar) desde otra perspectiva y a partir de «otro lenguaje». En realidad, ocurre que una nueva generación de escritores —en ningún sentido ajena, sino partícipe de una proyección vanguardista que anima a la intelectualidad

${ }^{2}$ Estas y otras referencias que aparecen en el texto pertenecen al prólogo que encabeza la edición del Teatro completo. «Piñera teatral», en Virgilio Piñera. Teatro completo (La Habana: Ediciones R, 1960). Con anterioridad, Piñera escribe dos piezas: Clamor en el penal y En esa helada zona, que no incluye en el volumen. 
cubana de estos años - ha entrado en escena, inaugura sus formas y reclama para sí otra manera de escribir y hacer teatro. Lo que separa Electra Garrigó (estrenada en 1948) de Tembladera, de Ramos, es el nacimiento de una nueva figuración. En treinta años surge una nueva sensibilidad dramática, aunque el impulso experimental, renovador de esta vanguardia, viera frenadas sus fuerzas y potencialidades artísticas por factores diversos ${ }^{3}$.

Varias veces he pensado que bastaría glosar (o reinterpretar, hasta donde sea posible) su excelente prólogo, de 1960, para situar a Piñera en el lugar que le corresponde en el teatro cubano. El dramaturgo enfrenta el desafío de una mirada crítica a su producción, y si algo hay que destacar especialmente es la absoluta honestidad de sus palabras. Pero no siempre el autor, cuando oficia de crítico, tiene toda la verdad. Veintisiete años después habría que hacerle justicia mayor. La obra que se iniciaba con una ruidosa «cubanización» del modelo, ni significaba sólo - como interpretó la crítica de la época- la «reducción» del mito griego a una suerte de «ajiaco» criollo en que las formas alambicadas de lo trágico perdían contorno y se entrelazaban a la comicidad, el choteo, la «resistencia» por el chiste. Significaba, además, la propuesta de integración de estratos diversos (lo «culto» y lo popular, lo nacional y lo universal) y una de las más serias reflexiones sobre la «cubanidad» realizadas en su tiempo. El tema de la «educación sentimental que nuestros padres nos han dado... ${ }^{4}$ impulsaba la cala profunda en valores regidos por la tradición; la rebeldía de Electra, la ironía del Pedagogo, ponían en tela de juicio concepciones caducas, y la parodia encubría, bajo su aparente jocosidad, claras y agudas verdades. La búsqueda de definiciones en torno a un «carácter del cubano» - pese a limitaciones o endebleces propias de orientaciones dominantes en el pensamiento de la época-constituía el núcleo de acción e indagación de la pieza. Más allá —o acá- de espejismos parciales (epocales), se situaba en el centro de una polémica no siempre bien resuelta ${ }^{5}$.

${ }^{3}$ Para una caracterización de la vanguardia teatral y las dificultades de su desarrollo pueden consultarse Rine Leal, Breve historia del teatro cubano (La Habana: Editorial Letras Cubanas, 1980); Raquel Carrió, «Una pelea cubana por la modernidad», revista Universidad de La Habana, núm. 22, -septiembre-diciembre 1983, y «Tres autores de transición», revista Tablas, La Habana, núm. 2, junio-diciembre, 1982.

${ }^{4}$ Virgilio Piñera, ed. cit.

${ }^{5}$ El debate sobre la «cubanidad» — la cubanía asumida como una condición agónicatiene claros antecedentes en el siglo xix. Se intensifica en las primeras décadas de la seudorepública y es retomado por el movimiento de vanguardia desde perspectivas diversas. En el caso de Piñera, Electra... corresponde a una primera formulación del problema, cuyo tratamiento evoluciona sucesivamente hasta Aire frio, donde convergen las coordenadas de la producción anterior. 
Curiosamente, Piñera ha sido un autor muy debatido pero poco estudiado. Eso explica que la crítica se haya detenido acaso excesivamente en zonas periféricas de su teatro (el tema de las «influencias»: Sartre, Ionesco, O'Neill...) y haya descuidado señalar aspectos que constituyen lo más significativo. Así, por ejemplo, raras veces se recuerda, a propósito del texto, que la parodia como recurso expresivo - y como intención estéticaproviene de la tradición popular. Si se recurre a las fuentes, se constata que un número considerable de piezas del repertorio de Alhambra no son sino reelaboraciones paródicas de tópicos y temas «clásicos» que permiten la integración de otros componentes: la música, el baile, el muestrario de tipos, el juego escénico, elementos que expresan el punto de vista popular, distanciado - y distanciador- del relato dramático ${ }^{6}$.

Vista en este sentido, Electra... no se reduce al mero divertimiento o a la crítica de una moral burguesa a través de uno de sus tópicos usuales. El humor, el grotesco de sus 'caracteres, son signos que remiten a una subversión de valores. La disección crítica de la familia Garrigó supone un punto de vista que distancia, crea el espacio de una subtextualidad que enriquece la acción. Lo negador, lo parodial, lo ecléctico en la obra, anunciaban de manera expresa lo que sería una constante en el teatro de Piñera: la búsqueda de un «género» —una modalidad genérica- capaz de integrar las fuentes y las formas de una cultura nacional. Un nuevo lenguaje (anticonvencional, negador, paródico), pero por ello mismo cargado de significaciones.

Como hecho aislado tendría poca importancia. Pero si se relaciona con una caracterización de la proyección vanguardista de estos años, puede medirse el alcance del texto. Si algo distingue la dramaturgia de la etapa es el interés por crear una expresión escénica que aborde asuntos, temas, personajes cubanos, pero a partir de técnicas modernas que garanticen su calidad estética y valor universal. Cubanía, modernidad y universalidad son conceptos que se unifican en un proyecto renovador con respecto a la tradición precedente, y en ningún caso la asimilación de influencias y modelos artísticos foráneos (surrealismo, existencialismo, teatro del absurdo o la crueldad) puede reducirse al criterio de "copia», reproducción mimética e indiscriminada. Por el contrario, el concepto mismo de «asimilación» supone un valor activo, selección y reelaboración creadora de

${ }^{6}$ Un estudio detenido del texto demuestra la presencia de elementos que Piñera desarrolia en obras posteriores: el absurdo, el humor, el grotesco como recursos distanciadores; el sentido de la «negación» y la opción de "partida» como oposición a un medio hostil, rechazable. Se relaciona con el esquema enajenación / desenajenación (aquí-ahora / allá-entonces) presente en una zona considerable de la literatura y el teatro republicanos. 
elementos que enriquecen una práctica artística. La «pelea por la modernidad» era también, y esencialmente, una vía de afirmación de lo cubano ${ }^{7}$.

Sintomáticamente, en varias ocasiones Piñera rechazó encasillamientos y etiquetas que la crítica impuso a su teatro. ¿Ingenuidad? ¿Autodefensa? ¿Alardes de «original»? Más bien la actitud de un autor que conoce sus intenciones, aunque no siempre esté en condiciones de realizarlas plenamente. Entre la escritura y el estreno de Electra... median siete años. Estimulado por la puesta en escena, escribe Jesús y Falsa alarma (1948). La primera llega a las tablas dos años después; la segunda tendrá que esperar hasta 1957. El hecho remite a razones conocidas. La condición precaria e inestable del movimiento teatral, la falta de apoyo oficial y la subestimación de obras y autores atentaron contra el desarrollo de la expresión dramática. Esas, y no otras razones, le hicieron sentirse un «casi autor teatral», un dramaturgo "proyecto» que pocas veces tuvo la posibilidad de confrontar su teatro con el público ${ }^{8}$.

Sin embargo, las piezas de estos años revelan con especial intensidad el proceso que lo conduce a Aire frío. Si la primera obra limita su indagación al medio familiar, si opera por yuxtaposición (el «modelo griego» y «lo cubano»), en Jesús la intención se amplía y gana en profundidad. Al contexto familiar sucede el «medio social», esta vez el tema de «los abismos a que puede ser llevado un hombre y un pueblo por la rupturá de los valores morales...» ${ }^{9}$. Lo que el texto refracta, en sus múltiples niveles de lectura, es el análisis minucioso, la disección de un estado de crisis de la conciencia nacional.

Aparentemente, el «texto» elude el «contexto». Pero cualquier conocedor de nuestra historia observa que en este caso la cala en la frustración nacional toca más hondo. El recurso de la negación (ya presente en Electra...: invocación a los no dioses, puerta de no partir) se profundiza y define su verdadera significación. Lo que se niega, en ambas obras, es un orden hostil, rechazable, que en la familia Garrigó genera actitudes paralizantes, destructivas (opción de partida, evasión en Orestes / permanencia y autodestrucción en Electra), y en Jesús —en virtud de esa ampliación

? Sería un error desvincular la reflexión sobre un «carácter del cubano» y las búsquedas en el terreno de los recursos expresivos. El substrato portador de significaciones —-búsqueda e indagación de «lo cubano»-genera un «sistema» de representación. La evolución conceptual y formal de este sistema constituye el aspecto de mayor interés en la dramaturgia en Piñera.

${ }^{8}$ Resulta iluminador en este sentido su artículo «Notas sobre el teatro cubano» (1966), publicado por la revista Tablas, La Habana, con el título «No estábamos arando en el mar» (núm. 2, abril-junio 1983).

9 Virgilio Piñera, ed. cit. 
de las escalas - asume los valores (supraindividuales, colectivos) de la impotencia y la pérdida de identidad.

Un estudio comparativo de los textos arroja luz sobre la trayectoria de Piñera. Al intento de «cubanización» sucede un ahondamiento en la mirada crítica. Lo paródico, el juego teatral, la «sistemática ruptura» de lo trágico por lo cósmico, la «reducción al absurdo» se subordinan como recursos expresivos al plano ideotemático. La situación es absurda en sí misma: el humor, el grotesco, la violencia y el sentido de la crueldad adquieren una dimensión que sobrepasa el nivel de la fábula. La obra se cierra sobre sí, anula el espacio: es el drama de la incomunicación y la impotencia. La rebeldía de Electra, la gozosa vitalidad de Clitemnestra Pla y Egisto Don, la posibilidad de partida de Orestes ceden terreno al ámbito cerrado en que la negación, la pérdida de identidad, la carencia de opciones prefiguran lo que será, en sentido más amplio, la década de los cincuenta en Cuba. Si Electra... abre la década anterior, Jesús anuncia la siguiente. Y, en cierta forma, prepara Aire frío ${ }^{10}$.

Es significativo que entre 1950 (puesta en escena de Jesús) y 1959 Piñera sólo estrena Falsa alarma, que reelabora para su montaje (1957), y La boda (1958). En la primera resultan evidentes las relaciones con la producción anterior, aunque el substrato portador de significaciones -la indagación sobre la cubanidad - se debilita o pierde fuerza en favor del diálogo brillante, el juego conceptual; en la segunda, pieza de circunstancia, parecen abandonarse las proyecciones iniciales. La lejanía, la carencia de una activa vinculación con el público y la escena, neutralizaron en alguna medida los primeros intentos.

Aun así, estas obras favorecieron un «oficio». Piñera marcha al extranjero y vuelve muchas veces. Las razones son harto conocidas: problemas económicos, pobreza del medio cultural cubano, imposibilidad para vivir de la profesión de escritor, rechazo de la situación del país. El resultado es Aire frío, esa pieza «sin argumento, sin tema, sin trama y sin desenlace...» que expresa, como ningún otro texto dramático del período, el proceso creciente de violencia y desintegración que caracteriza lo que fue — con palabras de Piñera— «miseria de nuestra vida ciudadana por cincuenta años...»

${ }^{10}$ Puede apreciarse un sentido de continuidad entre las obras que establecen la línea del teatro mayor de Piñera: Electra..., Jesús, Aire frío, Dos viejos pánicos. En especial, elementos de «atmósfera» que sugieren los textos: invocación a la luz, juego de transparencias (en Electra...); ensombrecimiento progresivo en Jesús, que permitirá el claroscuro en Aire frío y el universo opresivo en Dos viejos pánicos. 
Todo eso que, con mano temblorosa, con lágrimas en los ojos, he puesto en Aire frio, es decir, la historia de mi familia, que en resumidas cuentas es la historia de cualquier familia cubana de la clase media. ¡Clase media! Decirlo es una irrisión: nosotros hemos conocido desde las estrecheces de un cuarto para ocho hasta los pies descalzos y toda la gama y los matices del hambre. Somos clase media, pero también somos clase cuarta o décima..."

Con Aire frio, la dramaturgia cubana alcanza un nivel de realización no logrado hasta entonces. Asimila e incorpora los contenidos más fértiles de la tradición y, al mismo tiempo, genera nuevas vías. La historia muchas veces contada de la familia pequeño-burguesa cubana adquiere una dimensión que sobrepasa empeños anteriores: rompe esquemas de fíguración, sintetiza una trayectoria y crea el substrato que activará nuevas búsquedas y soluciones dramáticas.

Curiosamente, la obra rescata una tradición «realista». Pero no a la manera de la dramaturgia precedente. Las búsquedas en el terreno de los recursos expresivos, el sentido experimental, la activación de las formas que caracterizan el proyecto de vanguardia, enriquecen la mirada del autor en favor de una visión más compleja de lo real. Un concepto renovado de «realismo» sustenta la configuración de la imagen. Años después, Luz Marina y Oscar están derrotados de antemano. La partida de Oscar (prefigurada en Orestes), el estallido de Luz Marina dibujan la gestualidad de una clase que ha llegado al límite de sus posibilidades. La repetición, la ausencia de finalidad, la violencia y desintegración de valores devoran las figuras. Quizá es lo que le otorga una tragicidad no usual en nuestra dramaturgia. Lo que progresa en Aire frío es lo que Graziella Pogolotti ha llamado «la evidencia de una condición» ${ }^{12}$; pero el regreso de Oscar y el portazo de Luz Marina son signos que generan una nueva respuesta.

Por eso no es de extrañar que cuando, en 1962, se lleva a la escena se realice lo que podríamos llamar una lectura «abierta», descodificada del texto, posible por la perspectiva frente a la realidad cubana que brinda el triunfo revolucionario. El universo cerrado, condenado a la repetición y al deterioro progresivo de los personajes, se hace legible en sus contradicciones. Significaba el estallido, la quiebra de un mundo en el que imperan la alienación y la violencia. La mirada se «distancia», y de esta opción se deriva un conjunto de piezas significativas. Contigo pan y cebolla (1962), de Héctor Quintero; La casa vieja (1964), de Abelardo Estorino, y La

11 «Piñera teatral», ed. cit.

12 «... Lo que progresa es la evidencia de su condición. Prólogo a Teatro y revolución (La Habana: Editorial Letras Cubanas, 1980). 
noche de los asesinos (1965), de José Triana, establecen el sentido de continuidad de un legado de vanguardia. La búsqueda de un género nacional y popular, el debate sobre la cubanidad y la mirada al pasado que distinguen la dramaturgia de la década del sesenta, son líneas cuya matriz hay que localizar en Aire frío ${ }^{13}$.

Como en etapas anteriores, piezas de menor alcance preceden la elaboración de un texto mayor. Siempre se olvida algo (1964), El no (1965), La niñita querida (1966), las dos últimas inéditas, testimonian un autor en una etapa de búsquedas que no logra cristalizar hasta que, en 1968, Dos viejos pánicos obtiene el premio Casa de las Américas. Obra de madurez, rica en niveles de lecturas, abría un terreno de confrontaciones ${ }^{14}$.

Explicablemente, la crítica saludó la pieza por el carácter experimental de su concepción y el manejo de técnicas del teatro contemporáneo. Pero vaciló en otorgarle un nivel de representatividad en el reflejo de la nueva sociedad en transformación. El miedo, la vejez, la angustia por una vida de frustraciones no eran precisamente el signo de los nuevos tiempos. El universo cerrado de contradicciones, aislado del exterior, sin posibilidades de cambio o de ruptura, parecía anacronismo, desfasaje en el tiempo, reproducción «ahistórica» de un mundo condenado a desaparecer.

Sin embargo, hoy sabemos que era justamente allí donde residía la historicidad de la imagen. Si Electra... abre el teatro de vanguardia en Cuba, si Jesús profundiza en el sentido histórico de una imagen del cubano y Aire frío testimonia el clímax de la desintegración y la violencia en la vida nacional, Dos viejos pánicos significa el resultado orgánico, la culminación de una experiencia histórica, artística y humana. Es el drama de la senectud, la mirada al pasado que traza la caracterización de una clase que vio frustrados sus anhelos de realización en el medio social republicano. El espacio cerrado, la configuración ritual, la carencia de opciones estable-

${ }^{13}$ Puede intentarse el análisis de las correspondencias entre la crisis de valores en el universo que describe y las características estructurales de la obra. Rompe un sistema de representación: estallido desde dentro de estructuras que giran, fragmentadas. Explica la afirmación de Piñera ( ... una pieza sin argumento, sin tema, sin trama y sin desenlace...», ed. cit., p. 28) y se relaciona activamente con la dramaturgia de las décadas siguientes. En ella, la perspectiva se «distancia», clarifica la imagen y propicia una nueva interpretación del contexto.

14 Entre 1959-1968 escribe, además, El flaco y el gordo, El filántropo (publicadas en Teatro completo); La sorpresa (Lunes de revolución, La Habana, núm. 65, junio 27, 1960); El álbum (1965) (revista Conjunto, La Habana, núm. 61, Casa de las Américas, julio-diciembre 1984), entre otras. En la mayoría de los casos se trata de piezas breves o adaptaciones de cuentos del autor. En general, no definen un cambio sustancial en su producción, aunque revelen rasgos de interés. Puede consultarse: Bárbara Rivero, «Piñera inédito», en revista Tablas, La Habana, núm. 3, julio-septiembre 1985. 
cen la señal, inequívoca, de la culminación de una experiencia. En ese sentido, «matar el pasado» es el signo del texto y la clave de su aporte ${ }^{15}$.

Por otra parte, sería un error pensar que sólo el reflejo de la realidad inmediata constituye un legado a la cultura revolucionaria. En igual medida, cabe interrogarse qué del pasado nos conmueve o nos atrapa, nos impulsa a la reflexión o a la acción transformadora. Sintomáticamente, Piñera logra la imagen opresiva de un universo de valores periclitados sin posibilidades actuantes. La memoria, el juego de representaciones sustituyen la acción «real». Despedida de un mundo, juego de espejos, cierre y sacralización de una imagen que sintetiza una trayectoria. Del estreno de Electra Garrigó a Dos viejos pánicos han transcurrido veinte años. En dos décadas se inicia y llega a su madurez la propuesta de un teatro de vanguardia en Cuba.

Bastarían las obras mencionadas para considerarlo la figura mayor de la dramaturgia cubana contemporánea. Pero con una «residencia» que le era consustancial, Piñera siguió escribiendo hasta que, en su mesa de trabajo, dejó al morir la última pieza inconclusa. Una caja de zapatos vacía (1968), Handle with care (1969), Ejercicio de estilo (1969), Estudio en blanco y negro (1970), El Trac (1974), Un pico o una pala (1979) son textos que revelan una persistencia más allá del miedo, la vejez o el cambio de los tiempos. Son - para sorpresa del lector- ejercicios que no descansan en el nombre ganado, los temas de fácil aceptación o los recursos conseguidos. Se trata de exploraciones, búsquedas en el terreno de la técnica escénica que lo aproximan, conscientemente o no, a las nuevas tendencias teatrales de la década del setenta. Dos obras recientemente localizadas -Un arropamiento sartorial en la caverna platómica (1971) y Las escapatorias de Laura y Oscar (1973), en proceso de ediciónratifican el sentido experimental de su teatro y lanzan un nuevo reto a la interpretación ${ }^{16}$.

${ }^{15}$ Resulta de interés el estudio comparativo entre Dos viejos pánicos y La noche de los asesinos. En ambos casos la configuración ritual enfatiza el universo cerrado, estático, aislado del exterior: personajes apresados en contradicciones que no logran resolver. El espacio de recuperación es la memoria y el juego de representaciones sustituye la acción «real». Véase al respecto el estudio de Román de la Campa, José Triana: ritualización de la sociedad cubana, Institute for the Study of Ideologies and Literature, University of Minnesota, 1979.

${ }^{16}$ Estudio en blanco y negro fue publicada en Teatro breve hispanoamericano, selección, prólogo y notas por Carlos Solórzano (Madrid: Aguilar, 1970). Una caja de zapatos vacía, Handle with care, Ejercicio de estilo, El trac y Un pico o una pala (inconclusa al morir el autor), todas inéditas, se encuentran en proceso de publicación en una nueva edición del Teatro completo. Un arropamiento sartorial en la caverna platómica y Las escapatorias de Laura y Oscar se integran al volumen, a cargo del crítico e investigador Rine Leal. A él debo la información y las fechas de escritura de estas últimas piezas. 
En conjunto, las piezas escritas entre 1968 y 1979, si bien no significan una ruptura definitiva con el mundo de ideas y figuraciones de la producción anterior, evidencian una etapa de inconformidad, intento de renovar un sistema expresivo que ha alcanzado su plena conformación. Exploraciones en torno al «nacimiento» y significación de la palabra, el lenguaje gestual y la antinomia comunicación/incomunicación (pérdida de identidad/recuperación de un estado natural o primigenio, refundación y análisis del acto teatral) sugieren un área de reflexiones. Debe tenerse en cuenta que la «crisis del texto» (en Latinoamérica, en Cuba) no es un hecho casual. El agotamiento de los proyectos «modernizadores», la crisis del liberalismo y la necesidad de nuevas vías de transformación y desarrollo en el orden social explican el surgimiento de una nueva sensibilidad ante el teatro y las formas de comunicación. Un nuevo concepto de «modernidad» se impone a la escena y la escritura teatral. Más que «remanentes» de un viejo sistema, las últimas obras constituyen el índice de una zona transicional en la experiencia cultural cubana ${ }^{17}$.

Con Dos viejos pánicos, la dramaturgia de vanguardia culmina un ciclo de su trayectoria. Una renovación profunda — de los medios y los finessacudiría la escena nacional en la década siguiente. Pero ni el paso del tiempo ni las incomprensiones lograron silenciar a Piñera. Con lucidez, pensó siempre que su teatro cumplía una importante tarea de fundación y entrega:

... Nuestro objetivo es Cuba, la circunstancia cubana y el lapso de tiempo que la vida nos ha deparado en esta parte del mundo. Antes de mi entrada al teatro cubano habíamos tenido a Ramos, a Galarraga, etcétera; después han surgido otros nombres, y seguirán surgiendo hasta el momento en que podamos decir que nuestro teatro es tan eficaz como el francés, el ruso o el inglés. Eso es lo justo y es lo que todos esperamos... ${ }^{18}$

Con certeza, pensó que toda causa noble obliga a la justicia. En cualquier caso, se trataba de una hermosa «resistencia» fundadora.

Agosto 1987.

\footnotetext{
${ }_{17}$ Remito nuevamente al estudio de Román de la Campa, «Prólogo a José Triana», ob. cit.

${ }_{18}$ Virgilio Piñera, ed. cit.
} 